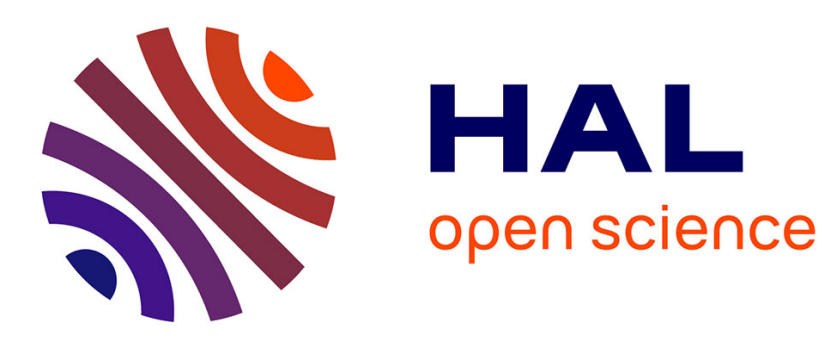

\title{
Potential of Lignins as Antioxidant Additive in Active Biodegradable Packaging Materials
}

Sandra Domenek, Abderrahim Louaifi, Alain Guinault, Stephanie Baumberger

\section{To cite this version:}

Sandra Domenek, Abderrahim Louaifi, Alain Guinault, Stephanie Baumberger. Potential of Lignins as Antioxidant Additive in Active Biodegradable Packaging Materials. Journal of Polymers and the Environment, 2013, 21 (3), pp.692-701. 10.1007/s10924-013-0570-6 . hal-00987129

\section{HAL Id: hal-00987129 \\ https://hal.science/hal-00987129}

Submitted on 5 May 2014

HAL is a multi-disciplinary open access archive for the deposit and dissemination of scientific research documents, whether they are published or not. The documents may come from teaching and research institutions in France or abroad, or from public or private research centers.
L'archive ouverte pluridisciplinaire HAL, est destinée au dépôt et à la diffusion de documents scientifiques de niveau recherche, publiés ou non, émanant des établissements d'enseignement et de recherche français ou étrangers, des laboratoires publics ou privés. 


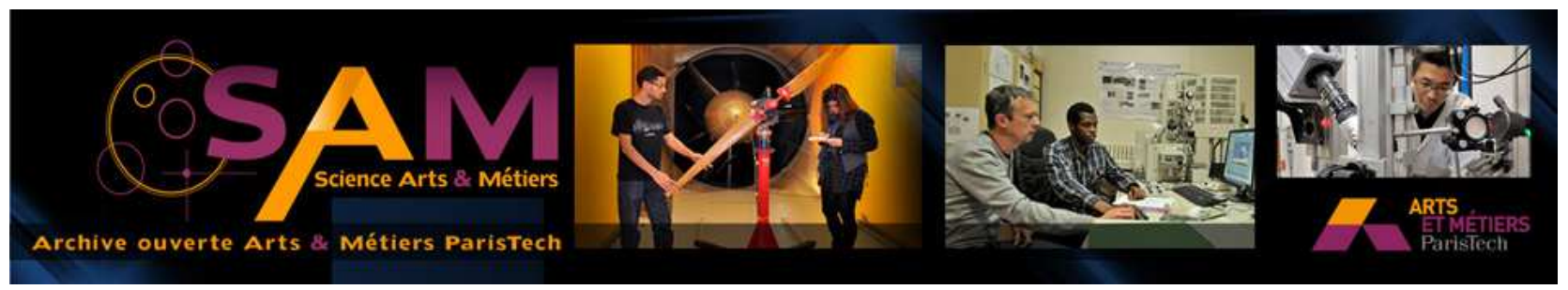

\section{Science Arts \& Métiers (SAM)}

is an open access repository that collects the work of Arts et Métiers ParisTech researchers and makes it freely available over the web where possible.

This is an author-deposited version published in: http://sam.ensam.eu

Handle ID: .http://hdl.handle.net/10985/8097

\section{To cite this version :}

Sandra DOMENEK, Abderrahim LOUAIFI, Alain GUINAULT, Stephanie BAUMBERGER -

Potential of Lignins as Antioxidant Additive in Active Biodegradable Packaging Materials - Journal of Polymers and the Environment - Vol. 21, n`3, p.692-701 - 2013 


\title{
Potential of Lignins as Antioxidant Additive in Active Biodegradable Packaging Materials
}

\author{
Sandra Domenek • Abderrahim Louaifi • \\ Alain Guinault $\cdot$ Stéphanie Baumberger
}

\begin{abstract}
Due to their polyphenolic structure lignins bear a number of interesting functional properties, such as antioxidant activity. Natural antioxidants are very much looked for in the aim of protection of light or oxygen sensitive goods and are being used in active packaging. Poly(lactide) (PLA)-lignin films were prepared by twin screw extrusion followed by thermo-compression using two different commercial sources of alkali lignins obtained from gramineous plants. A good dispersion of lignin in the matrix was observed. Mechanical properties of the compounded material were merely diminished and oxygen barrier properties slightly enhanced. The chromatographic study of the lignins revealed that the low molecular weight fraction of both lignins increased during the polymer processing. The migration of low molecular weight compounds in an ethanol/water solution simulating fatty foodstuff was performed and the antioxidant activity of the extract was analysed. It was found that the activity increases with increasing severity of the heat treatment because of the generation of free phenolic monomers
\end{abstract}

S. Domenek · A. Louaifi

AgroParisTech, UMR 1145, 91300 Massy, France

S. Domenek ( $\square)$

1, rue des Olympiades, 91744 Massy Cedex, France

e-mail: sandra.domenek@agroparistech.fr

S. Domenek

INRA, UMR 1145, 91300 Massy, France

A. Guinault

CNAM, PIMM- P2AM, 75141 Paris, France

S. Baumberger

Institut Jean-Pierre Bourgin, UMR 1318 AgroParisTech-INRA,

Pôle PAVE, 78000 Versailles, France during processing. These results open an interesting way for application of lignins as an active compound in packaging materials. Lignins do not impair the mechanical and barrier performance of the polymer and the plastics processing even allows for the generation of active substances.

Keywords Antioxidant - Food packaging - Lignin . Biodegradable polymer $\cdot$ Poly(lactic acid)

\section{Introduction}

Lignin is the second major component of wood and annual plants [1] after cellulose. Derivated from native lignin, industrial or technical lignins are available in large amounts as byproduct of the production of cellulose pulp in papermaking. Their quantity is supposed to keep increasing with the development of the lignocellulosic biorefinery and the production of second generation bioethanol. These by-products contain highly branched, irregular phenolic macromolecules, the structure of which is depending on botanic origin, harvesting period and extraction process. Industrial lignins are mainly used for energy production, but with regards to the huge amount available, valorization of a part of this abundant feedstock in high value applications is certainly attracting and also going to play a role in the economic feasibility of the production of bioethanol from lignocellulosic feedstocks $[2,3]$.

The blending of lignin with polymers has already been demonstrated [4]. Due to their aromatic structure and the occurrence of phenol residues, lignins have multiple functionalities, being able to act as compatibilizers [5], plasticizers [6], hydrophobizing agents [7, 8], flame retardants [9] or optical modifiers [10] or stabilizers [11]. Furthermore, properties potentially interesting in high value applications, 
such as antimicrobial activity [12] or cytotoxic effects [13] have been shown. The antioxidant properties of lignins stem from their radical scavenging capacity [13-17], following the general mechanism of monomeric phenols. The hindered phenolic hydroxyl groups being part of the lignin structure act as proton donors and are able to stabilize the radical in the quinone resonance structure [16]. Radical scavenging activity is described for a large number of lignin sources, ranging form black liquors [18] to the description of different botanic sources such as miscanthus [19], oak chips [20], bamboo [21] and many others. In general, radical scavenging activity of lignin is negatively influenced by increasing heterogeneity, dispersity, molecular weight average and carbohydrate admixtures [13, 15, 16]. Lignins extracted in sodium hydroxide aqueous medium (alkali lignins) have been shown to have higher activity than other types of lignins, such as lignosulfonates, Kraft, or steam explosion lignin, with a radical scavenging activity similar to that of epicatechin, used as a reference antioxidant [14, 17]. Alkali lignins contain a fraction of free phenolic monomers, mainly ferulic and p-coumaric acids [8], likely to account for this high radical scavenging activity.

In the field of material applications, the antioxidant activity has been investigated in the aim of using lignin as a natural substitute of synthetic antioxidants required for the formulation of polyolefins [22-25]. Pouteau et al. [26] showed that the compatibility between lignin and polymer matrix could be successfully predicted using the solubility parameters calculated after the Small, Van Krevelen and Hoy method.

The same mechanism protecting polyolefins against radical oxidative degradation is valuable for protection of fatty acids. The use of natural antioxidants to protect lipids and food has already long history [27-30]. For example, Ugartondo et al. [31] showed the capacity of lignin to prevent lipid peroxidation in human red blood cells. Polymer packaging materials are interacting with packed goods due to mass transfer between both partners, which is influencing food quality [32,33]. It is interesting to make positive use of such an interaction to ensure a sustained delivery of an active substance such as the antioxidant into the food stuff. In that aim, active packaging is now increasingly used as a reservoir for active substance delivery [34-37], complementing other techniques such as modified atmosphere packaging [38], edible coating [39, 40] or oxygen scavengers [41, 42].

The objective of the present study is to investigate the potential of lignin to be used as a natural antioxidant additive in an active food packaging. The packaging matrix chosen was poly(lactide) (PLA) because of its renewable character. The inclusion of natural antioxidants in PLA in the aim of developing an active material has already been suggested in literature [43-45]. Furthermore, some studies already exist pointing to the feasibility of inclusion of lignin into PLA [5, 9, 46, 47]. Two commercial alkali lignins were chosen because of their expected radical scavenging activity and their difference in the free phenolic monomers content. PLA was blended with lignin by twin screw extrusion and film samples were fabricated by thermo-compression. The effect of lignin quantity and processing on the radical scavenging activity was assessed in an ethanol/water solution being a stimulant of fatty foods recommended by the European regulation for food contact materials [48].

\section{Materials and Methods}

Poly(lactide), PLA 2002D, was purchased from NatureWorks (USA). Lignin PROTOBIND 1000, extracted by an alkali process from a mix of wheat straw (Triticum sp.) and sugar cane (Saccharum munja), and lignin SARKANDA, extracted by the same process from sugar cane (Saccharum munja), were obtained from GRANIT SA (Switzerland). Lignin PROTOBIND 1000 and SARKANDA differed in their content in free phenolic monomers: 8.0 and $0.5 \mathrm{mg} \mathrm{g}^{-1}$, respectively [8].

\section{Sample Preparation}

PLA was dried at $80{ }^{\circ} \mathrm{C}$ for $8 \mathrm{~h}$ in a SOMOS dryer (Mann \& Hummel ProTech, Germany). Final water content was around $720 \mathrm{ppm}$. Lignin powder was dried in an oven under vacuum at $60{ }^{\circ} \mathrm{C}$ for $15 \mathrm{~h}$. A dry blend of PLA pellets and lignin of desired quantity was realized and introduced into the feeder of a twin-screw extruder (Thermo-Haake Rheomix PTW 16/40, Germany). Barrel temperature was $180{ }^{\circ} \mathrm{C}$ and die temperature $170{ }^{\circ} \mathrm{C}$, rotating speed was set to $400 \mathrm{rpm}$. Throughput was fixed $1,000 \mathrm{~g} \mathrm{~h}^{-1}$. The extrudate was cooled in a water bath to room temperature and pelletized with the help of a Scamia (France) pelletizer. Pellets were then dried at $80{ }^{\circ} \mathrm{C}$ for $8 \mathrm{~h}$ under vacuum and stored over silica gel. Sample films were fabricated by thermocompression under a heating press (Télémécanique 15T N1, France) sandwiched between two Teflon sheets and two steel plates. Samples were melted for $2 \mathrm{~min}$ at $185^{\circ} \mathrm{C}$ without pressure, and then pressure was applied in three times to eliminate air bubbles: $30 \mathrm{~s}$ at $30 \mathrm{bar}, 30 \mathrm{~s}$ at $50 \mathrm{bar}$ and $1 \mathrm{~min}$ at $150 \mathrm{bar}$. In order to vary the heat treatment of the samples, the films were maintained in the heating press at $185^{\circ} \mathrm{C}$ under a pressure of 50 bar for different times. Films thickness, which was measured with a hand-held micrometer, lay between 200 and $300 \mu \mathrm{m}$. The PLA reference film was prepared only by thermo-compression.

\section{Material Characterization}

Lignin/PLA blend morphology was observed with the help of an transmission optical microscope (Nachet, France) on 
samples of $10 \mu \mathrm{m}$ thickness prepared by a microtome (Leica RM 2255, France).

Glass transition temperature $\left(\mathrm{T}_{\mathrm{g}}\right)$ and crystallinity degree $\left(\chi_{c}\right)$ were analyzed by differential scanning calorimetry (DSC). The DSC apparatus (Q100, TA Instruments, France) was calibrated with the help of indium and zinc standards before analysis. Samples $(10 \mathrm{mg})$ were loaded into hermetic aluminum crucibles (TZero) and a heat-cool-heat cycle was performed between 0 and $200{ }^{\circ} \mathrm{C}$ with a heating and cooling rate of $10{ }^{\circ} \mathrm{C} \mathrm{min}-1$. The enthalpy of PLA cold crystallization and melting was measured at the first heating run. The crystallinity degree $\left(\chi_{\mathrm{c}}\right)$ was calculated with Eq. 1, where $\Delta H_{m}$ is the enthalpy of melting, $\Delta H_{c c}$ is the enthalpy of cold crystallization and $\Delta H_{m}^{0}$ is the enthalpy of fusion per mol of repeating unit of the perfect crystal of infinite size, being $93 \mathrm{~J} \mathrm{~g}^{-1}$ [49]:

$\chi_{c}=\frac{\Delta H_{m}-\Delta H_{c c}}{\Delta H_{m}^{0}}$

The $\mathrm{T}_{\mathrm{g}}$ was measured in the second heating run on the midpoint of the heat capacity step. Analyses were carried out in triplicate.

The uniaxial tensile testing was carried out at room temperature and at $5 \mathrm{~mm} \mathrm{~min}^{-1}$ with an Instron tensile testing machine (Instron Model 4507) equipped with pneumatic jaws on type I BA dumbbell shaped samples (in accordance with the EN ISO 527 standard). Each value is an average of 5 measurements.

The oxygen transmission rate (OTR) was monitored at $23{ }^{\circ} \mathrm{C}, 0 \% \mathrm{RH}$, and a pressure gradient of 1 atm with a Systech 8001 apparatus. Oxygen permeability was then obtained by dividing the OTR by the film thickness. Film thickness was determined as the average of 9 thickness measurements on the film sample.

\section{Chromatography}

Molecular weight distribution of PLA, lignins and blends was determined by size exclusion chromatography (SEC). SEC was performed on a PL-gel mixed C column (Polymer Laboratories, $5 \mu \mathrm{m}, 600 \times 7.5 \mathrm{~mm}$ ) using stabilized THF (Carlo Erba SDS, HPLC quality) as eluent at a flow rate of $1 \mathrm{~mL} \mathrm{~min}^{-1}$. Detection was done by a diode array detector (Dionex Ultimate 3000, France) in series with a refractive index detector (Shodex RI 101, France). The lignin fraction was detected at $280 \mathrm{~nm}$ wavelength by the diode array detector and PLA by the refractive index detector. Injection volume was $10 \mu \mathrm{L}$. Calibration was performed with monodisperse polystyrene standards (EasyCal, Polymer Laboratories) with molecular weight ranging from 580 to 210,500 $\mathrm{g} \mathrm{mol}^{-1}$. Lignins and PLA-lignin blends were acetylated using a 1:2 pyridine/acetic anhydride mixture ( $\mathrm{v} / \mathrm{v}, 48 \mathrm{~h}$ at room temperature) and recovered according to
Gellerstedt [50] prior to SEC analysis. Solutions of acetylated lignins in tetrahydrofuran (about $10 \mathrm{mg} \mathrm{mL}^{-1}$ ) were ultrafiltrated on a $0.45 \mu \mathrm{m}$ PTFE filter (Millipore) before injection.

The identification and quantification of low molecular weight phenolic compounds migrating in an ethanol/water $(95 / 5 \mathrm{v} / \mathrm{v})$ solution was run on a polydimethylsiloxane capillary column (DB1, Supelco, $30 \times 0.25 \mathrm{~m}, 0.25 \mu \mathrm{m}$ ) GC/MS (Saturne 2100, Varian) with an ion trap spectrometer detector (IE $70 \mathrm{eV}$, positive mode) under helium

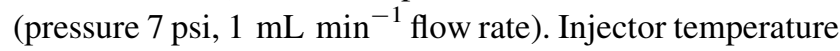
was $270{ }^{\circ} \mathrm{C}$. The temperature program was the following: a ramp from 40 to $110^{\circ} \mathrm{C}$ at $30^{\circ} \mathrm{C} \mathrm{min}^{-1}$, then from 110 to $200{ }^{\circ} \mathrm{C}$ at $2{ }^{\circ} \mathrm{C} \min ^{-1}$ and finally from 200 to $260{ }^{\circ} \mathrm{C}$ at $3{ }^{\circ} \mathrm{C} \min ^{-1}$. Sample preparation comprised a migration step from PLA and silylation. Migration was performed at room temperature for $48 \mathrm{~h}$ by immersion of $4 \mathrm{~cm}^{2}$ of film in $12 \mathrm{~mL}$ ethanol/water (95/5 v/v [48]) under stirring. After migration, the solvent was evaporated and the dry sample was weighted. Then it was adjusted in $100 \mu \mathrm{L}$ dichloromethane (Carlo Erba SDS) containing $0.495 \mathrm{mg} \mathrm{mL}^{-1}$ n-nonadecane (C19) and n-henicosane (C21) alkane standards (Sigma Aldrich). The solution was dried over $\mathrm{Na}_{2} \mathrm{SO}_{4}$ (Sigma Aldrich). An aliquot of $10 \mu \mathrm{L}$ was silylated by addition of $100 \mu \mathrm{L}$ trimethylsilyl(1E)-2,2,2-trifluoro$N$-(trimethylsilyl)ethanimidoate (BSTFA, Aldrich) and 10 $\mu \mathrm{L}$ pyridine (Merck). The reference solution was prepared in the same way and contained the following commercial phenols with a concentration of $1 \mathrm{mg} \mathrm{L}^{-1}$ : vanillin (Fluka, purum), syringaldehyde (Aldrich Chimie, purity $98 \%$ ), vanillic acid (Fluka, purum), syringic acid (Fluka, purum), $p$-coumaric acid (Sigma Aldrich) and ferulic acid (Fluka, purum). Semi-quantitative analysis was performed with response factors of the internal standards C21 and C19. Migrations were carried out in duplicate. Experimental error was $\pm 20 \%$.

\section{Antiradical Activity}

The antiradical activities of the films were probed using a spectroscopic method based on the disappearance of the absorption band at $515 \mathrm{~nm}$ of the free radical, 2,2-diphenyl1-picrylhydrazyl $\left(\mathrm{DPPH}^{\circ}\right)$ (Sigma-Aldrich, France) upon reduction by an antiradical compound [51]. The test consisted in adding $77 \mu \mathrm{L}$ of the antioxidant solution into $3 \mathrm{~mL}$ of a $\mathrm{DPPH}^{\circ}$ solution in methanol $\left(6 \times 10^{-5} \mathrm{~mol} \mathrm{~L}^{-1}\right)$ and following the intensity of the $515 \mathrm{~nm}$ absorption band over time (spectrophotometer Uvikon 810 Kontron, France). For the test of film samples, pieces of $1 \mathrm{~cm}^{2}$ were directly immersed into $3 \mathrm{~mL}$ of the methanolic $\mathrm{DPPH}^{\circ}$ solution. For the test of antiradical activity of migrating substances, $1 \mathrm{~cm}^{2}$ of film was immersed in $3 \mathrm{~mL}$ methanol or in $3 \mathrm{~mL}$ ethanol/water $(95 / 5 \mathrm{v} / \mathrm{v})$ for $24 \mathrm{~h}$ at ambient temperature. 
The ethanol/water mixture was used as simulant for fatty food, as suggested by the European Regulation, whereas methanol was used as widespread extraction solvent for phenolic monomers. The supernatant was recovered after $24 \mathrm{~h}$ and evaporated to dryness before being adjusted in $77 \mu \mathrm{L}$ methanol for the test. Experimental error of the determination of the remaining quantity of $\mathrm{DPPH}^{\circ}$ was $\pm 7 \%$. Ethanol (p.a. quality) and methanol (p.a. quality) were purchased by Carlo Erba.

\section{Results and Discussion}

\section{Composite Material Characteristics}

The material properties of the lignin/PLA blends were analyzed, in order to assure the quality of the packaging film. The two step process used in this study (twin screw extrusion and thermocompression) yielded a homogeneous dispersion of lignin particles of around 5-20 $\mu \mathrm{m}$ diameter inside the PLA matrix, which is shown in Fig. 1 for the example of lignin PROTOBIND 1000. The molecular weight distribution of PLA in the blended films and their mechanical, thermal and oxygen barrier properties are shown in Table 1. It can be observed on the neat sample that the sample fabrication process brought about a decrease in the molecular weight average $\left(M_{w}\right)$ of PLA. Such a decrease is often observed as PLA is very sensitive to thermohydrolysis caused by remaining traces of water [52]. The inclusion of lignin into PLA had no further effect on its $M_{w}$. The glass transition temperature $\left(\mathrm{T}_{\mathrm{g}}\right)$ of the lignin/PLA films was slightly lower than the one of the neat PLA, but no significant differences between the blends were detected. This may be attributed to a plasticizing effect. Indeed, a decrease of the $T_{g}$ of PLA due to the introduction of the natural antioxidant resveratrol was also observed by Hwang et al. [45] and explained by plasticizing. Moreover, aromatic molecules such as benzaldehyde have already shown their ability to decrease the $\mathrm{T}_{\mathrm{g}}$ of PLA [53]. The low molecular weight fraction of lignin has therefore probably a plasticizing effect. PLA/lignin films were amorphous under the given process conditions, no degree of crystallinity differences were observed and so no nucleating effect was observed. Results were the same for both lignin grades used.

As shown in Table 1, the inclusion of more than approximately $1 \mathrm{wt} \%$ of lignin decreased the yield stress, but it stays at a relatively high value. The elongation at break decreased slightly for the PLA/lignin SARKANDA formulation with the increase of lignin content. However, as PLA on itself is already a brittle material [54-58], further decrease was difficult to detect. The measured strain at break values of neat PLA data were in agreement with the
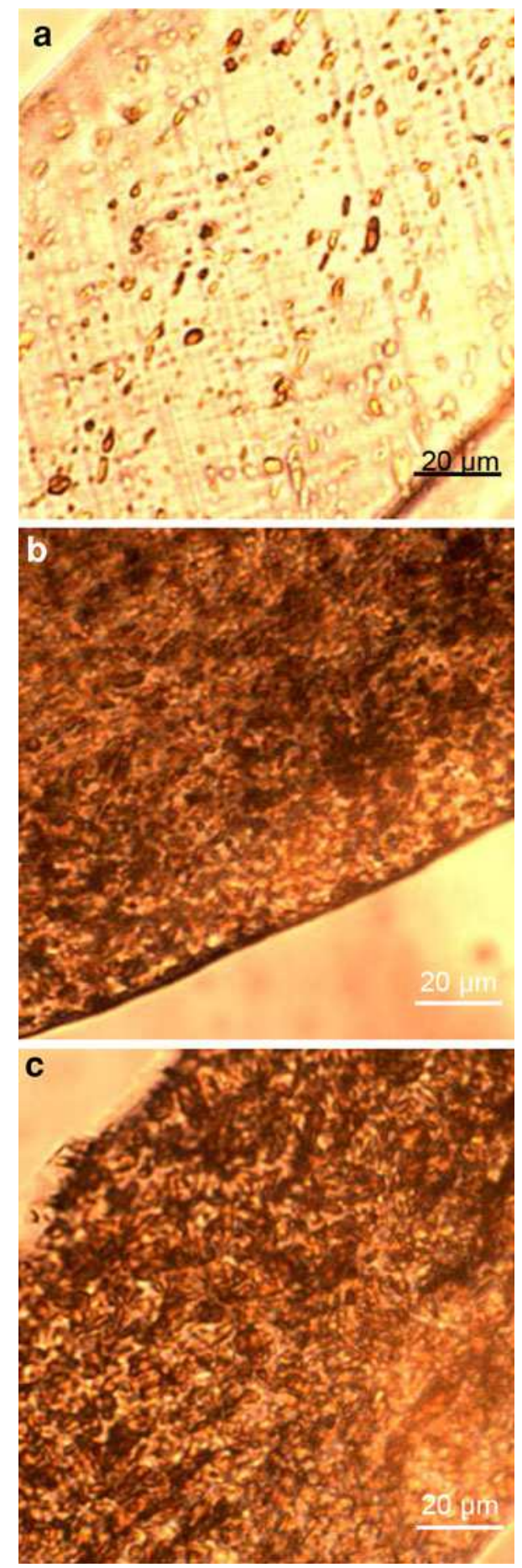

Fig. 1 Lignin distribution inside PLA obtained by twin screw extrusion and thermo-compression of PLA-PROTOBIND 1000 dry blend for 1 (a), 5 (b) and $10 \mathrm{wt} \%(\mathbf{c})$. Magnification $\times 50$

data given by the provider in the PLA 2002D datasheet and with literature results $[56,59]$. The relatively low decrease of yield stress and strain at break were certainly due to the counterbalance of two effects: the addition of high molecular mass lignin lead to increase of yield strength and 
Table 1 Physicochemical characteristics of PLA-lignin blends

\begin{tabular}{|c|c|c|c|c|c|c|c|c|}
\hline & Lignin (wt $\%)$ & $M_{w}(\mathrm{~g} / \mathrm{mol})$ & $\mathrm{I}_{\mathrm{p}}$ & $\mathrm{T}_{\mathrm{g}}\left({ }^{\circ} \mathrm{C}\right)$ & $\chi(\%)$ & $\sigma(\mathrm{MPa})$ & $\varepsilon(\%)$ & $\begin{array}{l}\mathrm{P}\left(\mathrm{O}_{2}\right) \times 10^{18} \\
\left(\mathrm{~m}^{3} \mathrm{~m} \mathrm{~m}^{-2} \mathrm{~s}^{-1} \mathrm{~Pa}^{-1}\right)\end{array}$ \\
\hline PLA pellets & & 209,000 & 1.18 & $60 \pm 1$ & $37 \pm 1$ & & & \\
\hline PLA film & & 139,000 & 1.91 & $61 \pm 1$ & $2 \pm 1$ & $67 \pm 3$ & $7 \pm 1$ & $2.3 \pm 0.3$ \\
\hline PLA/PROTOBIND 1000 & 1 & 142,000 & 1.81 & $55 \pm 1$ & $1 \pm 1$ & $55 \pm 6$ & $7 \pm 3$ & $2.1 \pm 0.1$ \\
\hline PLA/PROTOBIND 1000 & 5 & 151,000 & 1.64 & $53 \pm 2$ & $1 \pm 1$ & $56 \pm 3$ & $7 \pm 5$ & $2.0 \pm 0.1$ \\
\hline PLA/PROTOBIND 1000 & 10 & 132,000 & 1.87 & $51 \pm 2$ & $1 \pm 1$ & $52 \pm 8$ & $5 \pm 1$ & 1.8 \\
\hline PLA/SARKANDA & 1 & 126,000 & 1.74 & $56 \pm 1$ & $1 \pm 1$ & $56 \pm 8$ & $6 \pm 1$ & $2.2 \pm 0.1$ \\
\hline PLA/SARKANDA & 5 & 144,000 & 1.58 & $54 \pm 1$ & $1 \pm 1$ & $49 \pm 2$ & $4 \pm 1$ & $2.0 \pm 0.2$ \\
\hline PLA/SARKANDA & 10 & 135,000 & 1.71 & $52 \pm 2$ & $1 \pm 1$ & $53 \pm 2$ & $5 \pm 1$ & $1.7 \pm 0.1$ \\
\hline
\end{tabular}

$M_{w}$ molecular weight average, $I_{p}$ dispersity index, $T_{g}$ glass transition temperature, $\chi$ crystallinity degree, $\sigma$ yield stress, $\varepsilon$ strain at break, $P\left(O_{2}\right)$ oxygen permeability

decrease of strain at break, while the plasticization of PLA by low molecular mass lignin lead to decrease of yield strength and increase of strain at break. The effect of lignin on the mechanical properties data was also consistent with Ouyang et al. [46] who observed a decrease in the maximum strength for the blend of PLA/cellulolytic enzyme lignin and a slight decrease of strain at break. Comparable behaviour was also observed for PLA/Vanillex HW lignin samples [47]. In conclusion, the blending of PLA with lignin did not worsen the good mechanical performance of the materials. This pointed to compatibility between lignin and PLA, a result also pointed out by Ouyang et al. [46] and Li et al. [47]. This compatibility might be optimized in choosing proper lignin grades, following the suggestion of Pouteau et al. [26].

The oxygen barrier properties of the different materials are also given in Table 1 . Neat PLA oxygen barrier properties are in accordance with published data [54, 60-65]. Interestingly, the inclusion of at least $10 \mathrm{wt} \%$ of lignin yielded a decrease in oxygen permeability of around $20 \%$. As PLA crystallinity was not modified by the lignin addition, it would mean that lignin has probably lower oxygen permeability than PLA, and might therefore be able to introduce a barrier effect in the polymer.

In conclusion, the inclusion of both lignins at different weight percentages did not change notably the mechanical properties of PLA and even helped to improve oxygen barrier properties. Therefore, a valuable packaging film for rigid containers might be produced within the limits of application drawn by the intrinsic properties of PLA.

\section{Characteristics of the Lignin Charge}

The structural characteristics of the lignins in the PLA matrix were followed during the film fabrication process. The Fig. 2 shows the evolution of molecular weight distribution of the samples with the help of the chromatographic profile in UV detection. In agreement with Zheng et al. [8] the pure lignin samples (Fig. 2a) show a large molecular weight distribution indicating the presence of three populations: a polymeric fraction with low concentration yielding the tailing of the main peak towards small retention times, a oligomeric fraction present in higher concentration with a maximum about 17 min of retention time and then a monomeric fraction corresponding to the peak at $19.5 \mathrm{~min}$ only detected in PROTOBIND 1000. The $M_{w}$ of lignin PROTOBIND 1000 and SARKANDA was calculated to be of 3,000 and 2,600 $\mathrm{g} \mathrm{mol}^{-1}$, respectively, with, for both, a dispersity index of 3 . Such high dispersity indices are usually observed in the case of lignins $[8,66]$. The monomeric fraction present in PROTOBIND 1000 was previously found to be composed of $p$-coumaric and ferulic acid, acetosyringone, syringaldehyde and vanillin [8]. The superposition of chromatography profiles of the PLA/lignin blends with neat PLA are shown in Fig. 2b, c. PLA UV profile exhibited a peak at 21 min most probably due to the use of additives in the commercial PLA grade. Consequently, this peak was present on all the profiles and hindered the detection of possible low molecular weight compounds present in lignins. However, the retention time of the highest peak of PROTOBIND 1000 lignin shifted to slightly lower values (from 17 to $17.5 \mathrm{~min}$ ) and the shoulder detected at about $18 \mathrm{~min}$ and at $19 \mathrm{~min}$ seemed to increase (Fig. 2b), which suggested a decrease in the lignin molecular weight. In the case of SARKANDA lignin (Fig. 2c), the same shift to higher retention times (from 17 to $17.5 \mathrm{~min}$ ) of the main peak was observed and the appearance of a shoulder in the main peak at approximately $18.5 \mathrm{~min}$ retention time could be observed indicating that phenolic monomers were released during the blend processing. This monomeric fraction remained however in lower proportion than for PROTOBIND 1000 (Fig. 2b, c). The $M_{w}$ corresponding to the main distribution (peak at 21 min excluded) of the PLA-10 wt\% PROTOBIND 1000 and SARAKANDA 

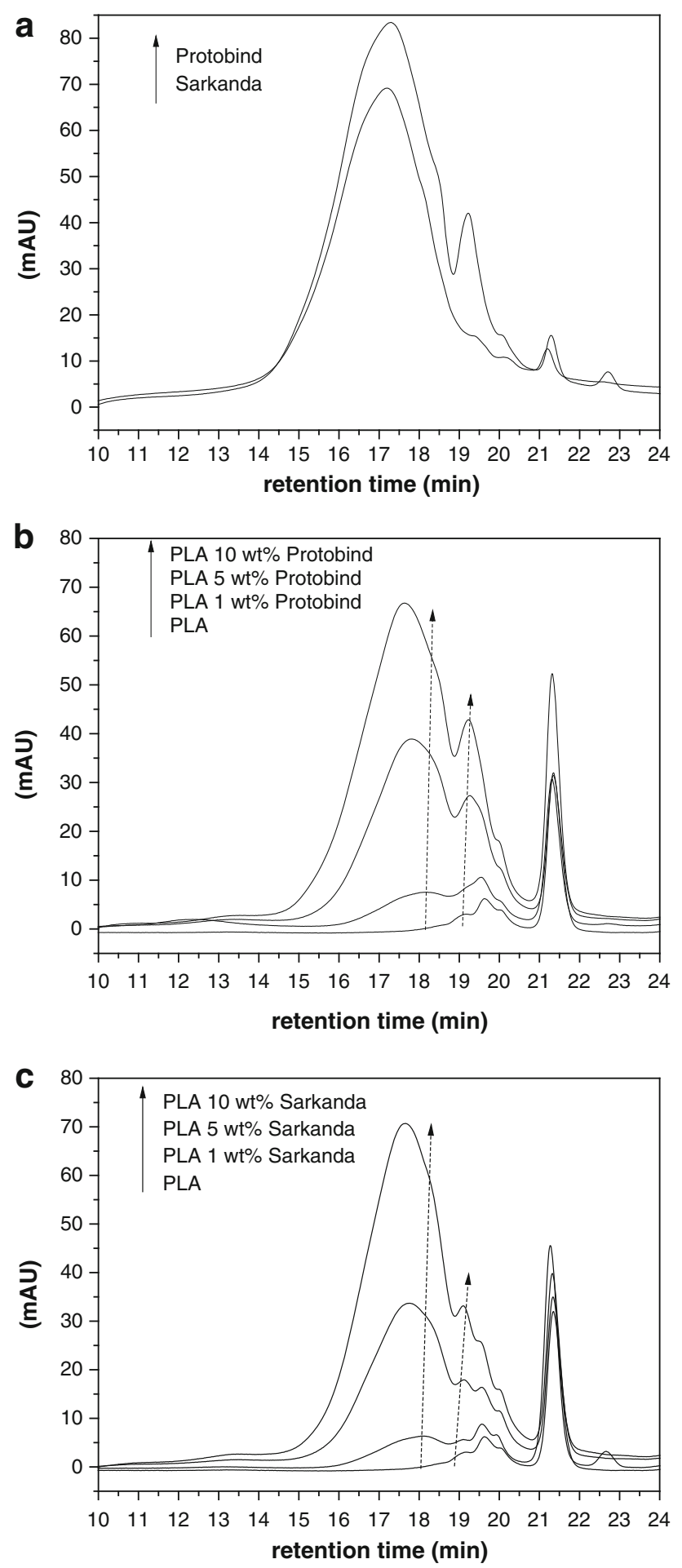

Fig. 2 Size exclusion chromatogram of lignins (a), PLA-PROTOBIND 1000 (b) and PLA-SARKANDA blends (c) fabricated by twin screw extrusion and thermocompression. Curves correspond to the order indicated by the arrow in the legend

blends was calculated to be $1,300 \mathrm{~g} \mathrm{~mol}^{-1}$, which corresponds to a $\sim 50 \%$ decrease with respect to the initial pure lignin samples.
In conclusion, upon thermal processing for film production, the proportion of low molecular weight compounds increased for both lignin grades, most probably as the consequence of lignin partial depolymerization. These molecules might be the origin of the plasticizing effect observed (Table 1) and discussed before. Furthermore, the low molecular weight fraction being composed of molecules carrying free phenols, the plastics processing might be able to generate additional molecules having an antiradical activity by the thermal degradation of the lignin charge.

\section{Antiradical Activity of PLA-Lignin Films}

Radicals originating from oxygen exist naturally in the atmosphere or can be created by thermal processing or irradiation of packaging and food [67]. Those radicals act as initiators of the chain oxidation of lipids. It is therefore interesting to eliminate theses radicals from the headspace and the bulk of the food, as an alternative route to eliminating oxygen from the package. The radical scavenging efficiency of an antiradical substance depends on the rate of hydrogen atom abstraction from the phenyl group and also on the stability of the resulting radical. Strategies employed in active packaging generally include (1) the design of active compound releasing systems and (2) undesired compound scavenging systems [68]. In the first strategy, the generation of low molecular weight substances inside the packaging film and promoting their migration into the foodstuff is interesting. In the second strategy, one of the advantages of radical scavengers is their efficiency upon contact without need for release of active compounds. This has been shown for hydroxyl radicals in the gas phase scavenged by essential oils supported on silanized glass wool and active packaging films containing essential oils [69]. The principle has been applied in the examples of use of catechins in poly(ethylene terephthtalate) [70] and catechins [71] or flavonoids in ethyl vinyl alcohol in using an adapted ORAC assay [72]. Although different methods exist to measure the radical scavenging activity of plastic films, the antiradical activity of the PLA-lignin film extracts was tested here with the help of the DPPH test, because it is readily available, largely used in literature and has already been employed for lignins [15]. Figure 3 shows the loss of the free radical $\mathrm{DPPH}^{\circ}$ with time for different PLA-PROTOBIND 1000 samples immersed directly in the methanol/DPPH ${ }^{\circ}$ solution. The neat PLA sample did not show any activity. Furthermore, it can be observed that the oxidative capacity of the film increased with increasing quantity of PROTOBIND 1000, as shown by the lower plateau value of the residual $\mathrm{DPPH}^{\circ}$. Only $1 \mathrm{wt} \%$ PROTOBIND 1000 yielded very small decrease of the $\mathrm{DPPH}^{\circ}$ concentration, and the signal was very noisy in the 
beginning, while the $10 \mathrm{wt} \%$ PROTOBIND 1000 film reached a plateau value of $42 \%$ remaining $\mathrm{DPPH}^{\circ}$. The films themselves seemed to show an antiradical activity. Interestingly, the PLA-PROTOBIND 1000 film sample shown in Fig. 3 was extracted for $24 \mathrm{~h}$ in ethanol/water $(95 / 5 \mathrm{v} / \mathrm{v})$. The same film sample was then immersed in the methanol/ $/ \mathrm{DPPH}^{\circ}$ solution a second time and the decrease of the $\mathrm{DPPH}^{\circ}$ absorbance measured. It had still the possibility of oxidizing the $\mathrm{DPPH}^{\circ}$ radical. This shows that a sustained protective action for food due to slow release kinetics might be possible. It is worth noting however that with the experimental setup scavenging effects on the

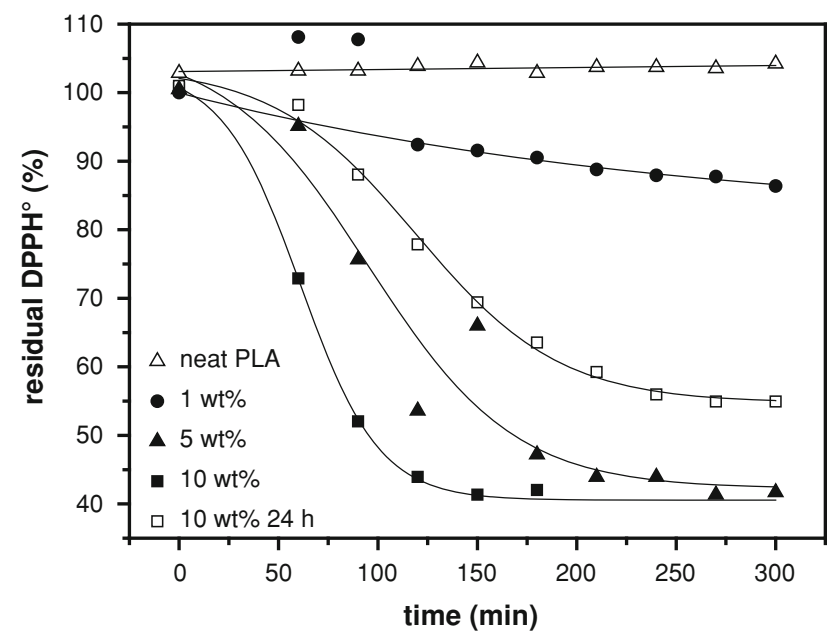

Fig. 3 Reaction kinetics of the free radical $\mathrm{DPPH}^{\circ}$ during immersion of PLA-PROTOBIND 1000 films in the methanol solution. The sample indicated with $24 \mathrm{~h}$ was measured a second time after being extracted for $24 \mathrm{~h}$ in ethanol/water $(95 / 5 \mathrm{v} / \mathrm{v})$. Lines are drawn to guide the eye surface cannot be clearly separated from effects due to surface release of phenolic compounds.

Therefore, the lignins and PLA-lignin films were immersed in a migration solution and the quantity of extracted phenolic compounds was assessed with the help of a semi-quantitative chromatography method (Fig. 4). In order to simulate fatty foodstuff, a solution of $95 \%$ ethanol in water $(\mathrm{v} / \mathrm{v})$ was used as proposed by the European regulation for food contact materials [48]. The data in Fig. 4a confirmed that the content of possibly migrating free phenolic monomers in PROTOBIND 1000 is higher than in SARKANDA. The recovered quantity was much lower than the content of approximately 8 and $5 \mathrm{mg} / \mathrm{g}$ in PROTOBIND 1000 and SARKANDA, respectively, which was determined by Zheng et al. [8] with the help of a solvent extraction method. Ethanol/water is certainly a much less efficient extraction solvent compared to ethyl acetate/ dichloromethane used by Zheng et al. [8]. The dashed line signifies the false detection level due to bleeding of the chromatography column. It can be observed in Fig. 4b that the migration from the PLA-lignin films with only $1 \mathrm{wt} \%$ of inclusion was not significant in the case of SARKANDA and very small in the case of PROTOBIND 1000. The detected quantities of free phenolic monomers in the migration solution formed two groups, where the higher group included only the PROTOBIND 1000 blends.

The antiradical activity of the different migrates from the PROTOBIND 1000 blends with increasing quantities of lignin was tested by the decrease of the concentration of the free radical of $\mathrm{DPPH}^{\circ}$ in function of time (Fig. 5). The reaction kinetics of the PLA-1 wt\% PROTOBIND 1000 film migrate was much slower than the kinetics of the 5 and $10 \mathrm{wt} \%$ PLA-PROTOBIND 1000 migrates because of the
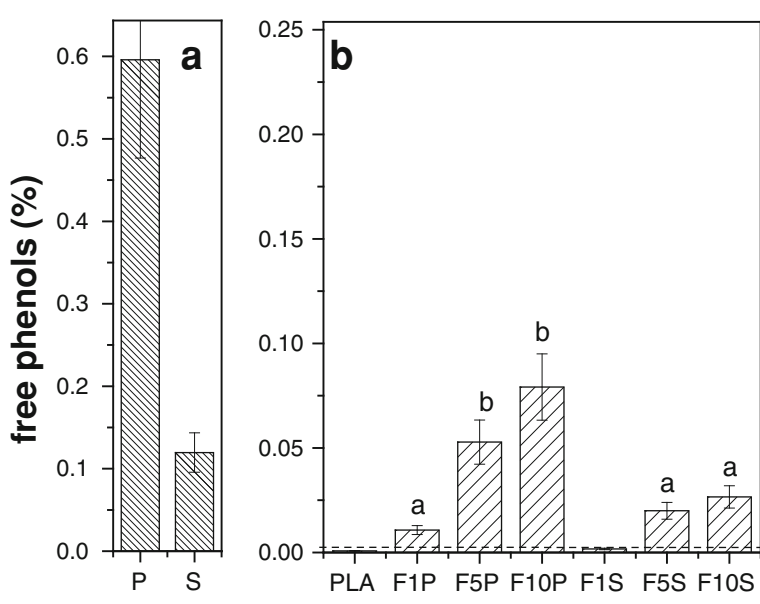

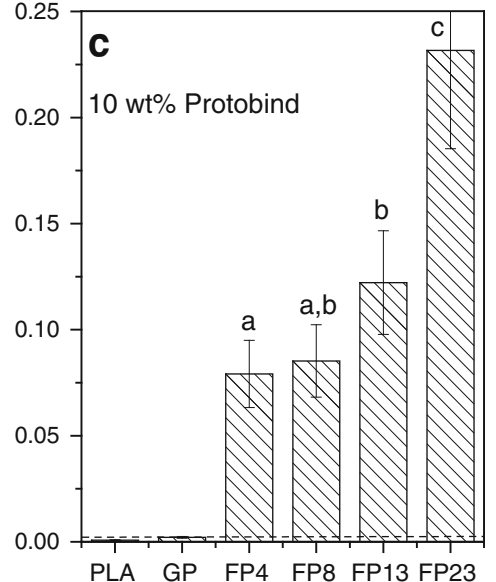

Fig. 4 Semi-quantitative gas chromatography determination of the migration of free phenolic monomers from PLA-lignin blends into ethanol/water $(95 / 5 \mathrm{v} / \mathrm{v})$ at room temperature for $24 \mathrm{~h}$. The letters $a$, $b$ and $c$ correspond to statistical different groups. The dashed line marks the quantity detected due to column bleeding. Sample codes: In b the codes indicate film samples with different quantities $(\mathrm{x}=1,5$ or $10 \mathrm{wt} \%$ ) of PROTOBIND 1000 (P) or SARKANDA (S). In c PLA$10 \mathrm{wt} \%$ PROTOBIND 1000 film samples are coded with the length of the heat treatment "FPt", where $\mathrm{t}=4,8,13$ and $23 \mathrm{~min}$. GP are the pellets of PLA-10 wt\% PROTOBIND 1000 


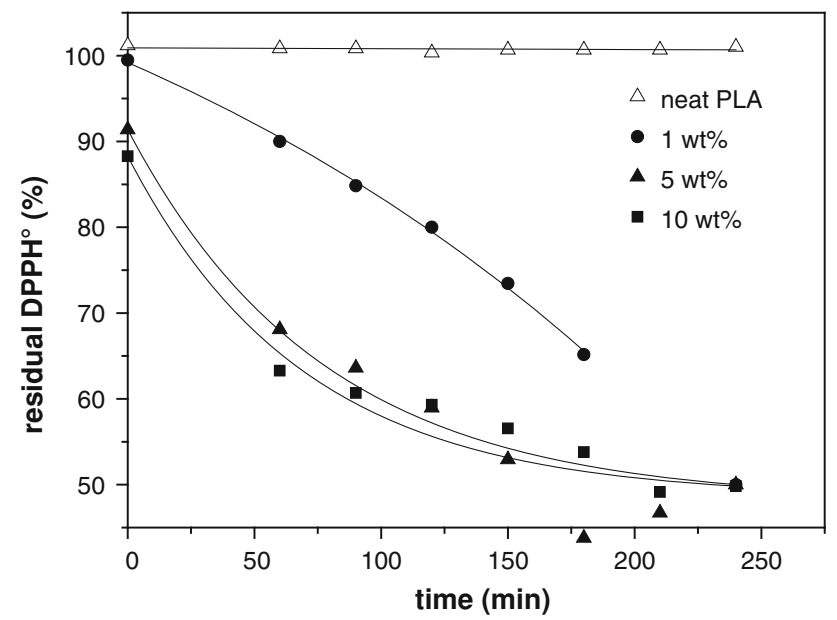

Fig. 5 Reaction kinetics of the free radical $\mathrm{DPPH}^{\circ}$ with migrates of neat PLA (open triangle) and PLA-PROTOBIND 1000 samples in ethanol/water $(95 / 5 \mathrm{v} / \mathrm{v})$ for $24 \mathrm{~h}$ at room temperature. Lines are drawn to guide the eye

very small quantity of migrating substances, already observed in Fig. 4b. The inclusion of only $1 \mathrm{wt} \%$ lignin was therefore be not enough to yield sufficient release from the matrix within the experimental time frame used to obtain an antiradical activity. No differences between the two higher concentrations were observed. The concentration of remaining $\mathrm{DPPH}^{\circ}$ stabilized between around $50 \%$ after $200 \mathrm{~min}$. Kinetics are consistent with data given for slower reacting antioxidants like guaiacol [51]. The absolute plateau value of $\mathrm{DPPH}^{\circ}$ cannot be compared with known substances, as it depends on the moles of antioxidant introduced. In the present case, the extract of the PLAlignin films was a mixture of different substances and quantification of the free phenolic monomers was carried out only on the identified structures in the gas chromatogram. Therefore, the antiradical power of the migrate could not be determined.

In order to further investigate the effect of thermal processing on the release of free phenols, the film samples of PLA/PROTOBIND 1000 were thermocompressed for increasing times. The evolution in Fig. $4 \mathrm{c}$ showed that there is an augmentation in free phenolic compounds recovered in the migration solution which is correlated to the length of the thermal treatment. The samples separated into three groups where the sample treated $8 \mathrm{~min}$ corresponded to the middle group. The antiradical activity of the migration solutions of thermally treated PLA-lignin films was measured and results are plotted in Fig. 6. The plateau value of remaining $\mathrm{DPPH}^{\circ}$ decreases with increasing thermal treatment. Two different groups were identified, the PLA-lignin pellets and the film treated for $4 \mathrm{~min}$ in one group (plateau values between 55 and $65 \%$ ) and the other films separated in a second group of higher activity

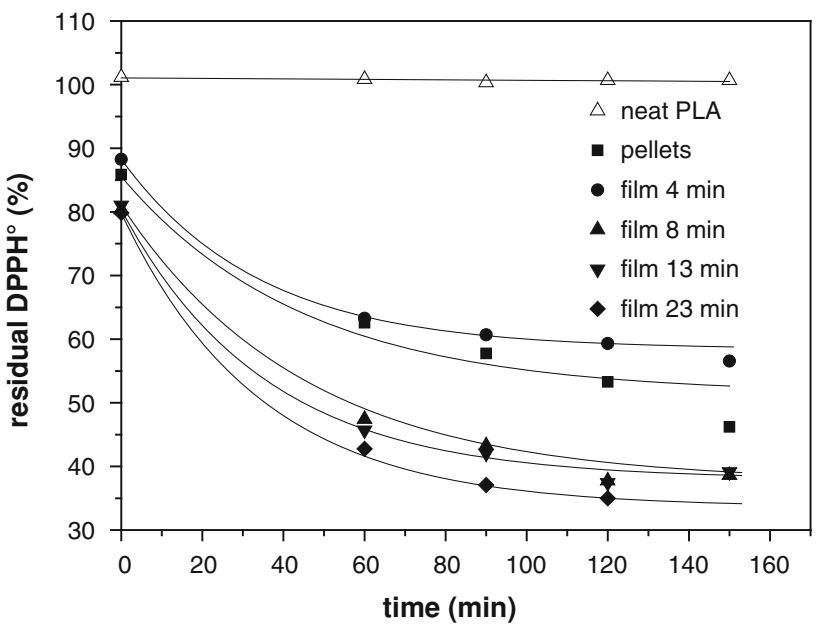

Fig. 6 Reaction kinetics of the free radical $\mathrm{DPPH}^{\circ}$ with migrates in ethanol/water $(95 / 5 \mathrm{v} / \mathrm{v})$ of PLA-lignin samples containing $10 \mathrm{wt} \%$ lignin PROTOBIND 1000 after different heat treatments. Lines are drawn to guide the eye

(plateau values between 35 and $41 \%$ ). This result is consistent with the observation that the total quantity of the low molecular weight fraction of lignin increases with the thermal severity of processing (Fig. 4c). However, in Fig. $4 \mathrm{c}$ were identified 3 different groups, which were not found in the $\mathrm{DPPH}^{\circ}$ test. Probably, the $\mathrm{DPPH}^{\circ}$ test is more sensitive to variations in the quantity of antiradical substances. Furthermore, not all phenols have the same antioxidant power, which means that at in sum equal quantity differences in the antiradical efficiency can be expected. More detailed investigation of the quantity of each antiradical species will be required to deepen this question.

\section{Conclusions}

PLA-lignin films with two different sources of lignin, PROTOBIND 1000 and SARKANDA, were prepared by a two step twin screw extrusion and thermo-compression process and the characteristics of the composites were measured. Lignin and PLA were immiscible and distribution of lignin is homogeneous inside the matrix. Mechanical properties of the blends were only slightly diminished due to a counterbalancing effect between the reinforcement by the high molecular weight lignin and the plasticization by the low molecular weight lignin compounds and oxygen barrier properties were even slightly but significantly enhanced. The study of the lignin component revealed that the low molecular weight fraction of both lignins increased during processing. The immersion of the PLA-PROTOBIND 1000 film into the fatty food simulant yielded migration of radical scavengers into the solution as determined by the $\mathrm{DPPH}^{\circ}$ test and the antiradical efficiency 
increased with increasing severity of the heat treatment of the blends. This result opens the door to the fabrication of active packaging materials compounded with the natural antioxidant lignin as that they do not impact the mechanical and barrier performance of the polymer and even allow the creation of more active substances during the polymer processing. Further investigation of the kinetics of generation of antiradical substances and the identification of their respective antiradical power is now required to explore the feasibility of the process.

Acknowledgments The authors acknowledge the scientific research fund of AgroParisTech for funding.

\section{References}

1. Boudet AM, Lapierre C, Grimapettenati J (1995) New Phytol 129:203

2. Stewart D (2008) Ind Crops Prod 27:202

3. Doherty WOS, Mousavioun P, Fellows CM (2011) Ind Crops Prod 33:259

4. Lora JH, Glasser WG (2002) J Polym Environ 10:39

5. Graupner N (2008) J Mater Sci 43:5222

6. Baumberger S, Lapierre C, Monties B (1998) J Agric Food Chem 46:2234

7. Baumberger S, Lapierre C, Monties B, Della Valle G (1998) Polym Degrad Stab 59:273

8. Zheng D, Méchin V, Pollet B, Dole P, Coqueret X, Baumberger S (2008) In: 10th EWLP, European Workshop on Lignocellulosics and Pulp, KTH, Royal Institute of Technology, Stockholm, pp 380-383

9. Reti C, Casetta M, Duquesne S, Bourbigot S, Delobel R (2008) Polym Adv Technol 19:628

10. Toh K, Nakano S, Yokoyama H, Ebe K, Gotoh K, Noda H (2005) Polym J 37:633

11. Pucciariello R, D'Auria M, Villani V, Giammarino G, Gorrasi G, Shulga G (2010) J Polym Environ 18:326

12. Cruz JM, Dominguez JM, Dominguez H, Parajo JC (2001) J Agric Food Chem 49:2459

13. Ugartondo V, Mitjans M, Vinardell MP (2008) Bioresour Technol 99:6683

14. Vinardell MP, Ugartondo V, Mitjans M (2008) Ind Crops Prod 27:220

15. Dizhbite T (2004) Bioresour Technol 95:309

16. Pan XJ, Kadla JF, Ehara K, Gilkes N, Saddler JN (2006) J Agric Food Chem 54:5806

17. Lu Q, Liu WJ, Yang L, Zu YG, Zu BS, Zhu MH, Zhang Y, Zhang XN, Zhang RR, Sun Z, Huang JM, Zhang XN, Li WG (2012) Food Chem 131:313

18. Faustino H, Gil N, Baptista C, Duarte AP (2010) Molecules 15:9308

19. Garcia A, Toledano A, Andres MA, Labidi J (2010) Process Biochem 45:935

20. Karvela E, Makris DP, Kefalas P, Moutounet M (2008) Food Chem 110:263

21. Li M-F, Sun S-N, Xu F, Sun R-C (2012) J Agric Food Chem 60:1703

22. Alexy P, Kosikova B, Crkonova G, Gregorova A, Martis P (2004) J Appl Polym Sci 94:1855

23. Gregorova A, Kosikova B, Stasko A (2007) J Appl Polym Sci 106:1626
24. Mengeloglu F, Karakus K (2008) Fresenius Environ Bull 17:211

25. Samal SK, Fernandes EG, Corti A, Chiellini E (2009) Int J Mater Prod Technol 36:62

26. Pouteau C, Baumberger S, Cathala B, Dole P (2004) C R Biol 327:935

27. Dinis TCP, Madeira VMC, Almeida LM (1994) Arch Biochem Biophys 315:161

28. Frankel EN (1996) Food Chem 57:51

29. Shahidi F (2000) Nahrung Food 44:158

30. Bentayeb K, Rubio C, Sanchez C, Battle R, Nerin C (2007) Ital J Food Sci: 110

31. Ugartondo V, Mitjans M, Pilar Vinardell M (2009) Ind Crops Prod 30:184

32. Berlinet C, Ducruet V, Brillouet JM, Reynes M, Brat P (2005) Food Addit Contam Part A Chem Anal Control Expo Risk Assess 22:185

33. Saint-Eve A, Levy C, Le Moigne M, Ducruet V, Souchon I (2008) Food Chem 110:285

34. Lopez-de-Dicastillo C, Gomez-Estaca J, Catala R, Gavara R, Hernandez-Munoz P (2012) Food Chem 131:1376

35. Pereira de Abreu DA, Maroto J, Rodriguez KV, Cruz JM (2012) J Sci Food Agric 92:427

36. Nerin C, Tovar L, Djenane D, Camo J, Salafranca J, Beltran JA, Roncales P (2006) J Agric Food Chem 54:7840

37. Wessling C, Nielsen T, Giacin JR (2001) J Sci Food Agric 81:194

38. Van Bree I, De Meulenaer B, Samapundo S, Vermeulen A, Ragaert P, Maes KC, De Baets B, Devlieghere F (2010) Innov Food Sci Emerg Technol 11:511

39. Hambleton A, Voilley A, Debeaufort F (2012) Food Hydrocoll 25:1128

40. Karbowiak T, Debeaufort F, Voilley A, Trystram G (2009) Innov Food Sci Emerg Technol 10:116

41. Antunez PD, Omary MB, Rosentrater KA, Pascall M, Winstone L (2012) J Food Sci 77:S1

42. Cardona ED, Noriega MD, Sierra JD (2012) J Plast Film Sheet 28:63

43. Soto-Valdez H, Auras R, Peralta E (2011) J Appl Polym Sci 121:970

44. Manzanarez-Lopez F, Soto-Valdez H, Auras R, Peralta E (2011) J Food Eng 104:508

45. Hwang SW, Shim JK, Selke SE, Soto-Valdez H, Matuana L, Rubino M, Auras R (2012) Polym Int 61:418

46. Ouyang WZ, Huang Y, Luo HJ, Wang DS (2012) J Polym Environ 20:1

47. Li JC, He Y, Inoue Y (2003) Polym Int 52:949

48. 97/48/EC D, Directive 97/48/EC of the European Commission. Official Journal of the European Communities (29 July 1997)

49. Fischer E, Sterzel H, Wegner G (1973) Kolloid-Zeitschrift Zeitschrift für Polymere 251:980

50. Gellerstedt G (1992) In: Lin Y, Dence C (eds) Methods in lignin chemistry. Springer-Verlag, Berlin, pp 485-523

51. Brand Williams W, Cuvelier ME, Berset C (1995) Food Sci Technol Lebensm Wiss Technol 28:25

52. Lim LT, Auras R, Rubino M (2008) Prog Polym Sci 33:820

53. Salazar R, Domenek S, Courgneau C, Ducruet V (2012) Polym Degrad Stab 97:1871

54. Courgneau C, Domenek S, Lebosse R, Guinault A, Averous L, Ducruet V (2012) Polym Int 61:180

55. Pillin I, Montrelay N, Grohens Y (2006) Polymer 47:4676

56. Domenek S, Courgneau C, Ducruet V (2011) In: Kalia S, Averous L (eds) Biopolymers: biomedical and environmental applications. John Wiley \& Scrivener Pub., pp 183-223

57. Martino VP, Ruseckaite RA, Jiménez A (2009) Polym Int 58:437

58. Elangovan D, Yuzay IE, Emselke S, Auras R (2011) Polym Int $61: 30$

59. Auras R, Harte B, Selke S (2004) Macromol Biosci 4:835 
60. Colomines G, Ducruet V, Courgneau C, Guinault A, Domenek S (2010) Polym Int 59:818

61. Auras RA, Harte B, Selke S, Hernandez R (2003) J Plast Film Sheet 19:123

62. Guinault A, Sollogoub C, Ducruet V, Domenek S (2012) Eur Polym J 48:779

63. Drieskens M, Peeters R, Mullens J, Franco D, Lemstra PJ, Hristova-Bogaerds DG (2009) J Polym Sci Part B Polym Phys 47:2247

64. Sawada H, Takahashi Y, Miyata S, Kanehashi S, Sato S, Nagai K (2010) Trans Mater Res Soc Jpn 35:241

65. Courgneau C, Domenek S, Guinault A, Averous L, Ducruet V (2011) J Polym Environ 19:362
66. Baumberger S, Abaecherli A, Fasching M, Gellerstedt G, Gosselink R, Hortling B, Li J, Saake B, de Jong E (2007) Holzforschung 61:459

67. López-de-Dicastillo C, Pezo D, Nerín C, López-Carballo G, Catalá R, Gavara R, Hernández-Muñoz P (2012) Packag Technol Sci. doi:10.1002/pts.992

68. Nerin C, Tovar L, Salafranca J (2008) J Food Eng 84:313

69. Pezo D, Salafranca J, Nerin C (2008) J Chromatogr A 1178:126

70. Colon M, Nerin C (2012) J Agric Food Chem 60:9842

71. Lopez de Dicastillo C, Nerin C, Alfaro P, Catala R, Gavara R, Hernandez-Munoz P (2011) J Agric Food Chem 59:7832

72. Bentayeb K, Vera P, Rubio C, Nerin C (2009) Anal Bioanal Chem 394:903 